\title{
INTERNACIONALIZAÇÃO DOS INSTITUTOS DE PESQUISAS TECNOLÓGICAS
}

\author{
Fabiano Manfio \\ fabianomanfio@yahoo.com.br \\ Universidade Federal do Paraná - Curitiba, PR / Brasil \\ João Carlos da Cunha \\ jccunhaisat@gmail.com \\ Universidade Federal do Paraná - Curitiba, PR / Brasil
}

Recebido em 24/06/2009

Aprovado em 26/09/2011

Disponibilizado em 01/04/2012

Avaliado pelo sistema double blind review

Revista Eletrônica de Administração

Editor: Luís Felipe Nascimento

ISSN 1413-2311 (versão on-line)

Editada pela Escola de Administração da Universidade Federal do Rio Grande do Sul.

Periodicidade: Quadrimestral

Sistema requerido: Adobe Acrobat Reader.

\section{RESUMO}

O estudo da internacionalização das organizações emerge do processo de interação e troca entre organizações de diferentes países, em especial nas organizações comerciais e industriais. O foco deste estudo é a internacionalização dos Institutos de Pesquisas Tecnológicas - IPTs. Os estudos de caso foram realizados em três instituições: Instituto Brasileiro de Tecnologia do Couro, Calçado e Artefatos - IBTeC -, Instituto de Tecnologia para o Desenvolvimento LACTEC e Instituto de Pesquisa Tecnológica do Estado de São Paulo - IPT®. A operacionalização da pesquisa ocorreu por meio de entrevistas semiestruturadas realizadas com diretores e pesquisadores, análise documental com material institucional de divulgação, relatórios de gestão, relatórios técnicos e outros documentos administrativos e observação direta por ocasião das visitas às instituições. As análises mostraram que as principais ações de internacionalização dos Institutos de Pesquisas Tecnológicas - IPTs - pesquisados ocorrem a partir das relações pessoais de seus pesquisadores. A internacionalização acontece principalmente em atividades de qualificação técnica, ficando as parcerias formais e a venda de serviços em segundo plano. Os resultados revelaram também uma grande diversidade de atividades internacionais desenvolvidas, contudo essas atividades caracterizam-se como de "baixa intensidade" quando comparadas com as atividades desenvolvidas pelos IPTs no país.

Palavras-chave: Institutos de Pesquisas Tecnológicas; Internacionalização; Atividades de Internacionalização; Resultados da Internacionalização. 
Fabiano Manfio \& João Carlos da Cunha

\title{
INTERNATIONALIZATION OF THE TECHNOLOGICAL RESEARCH INSTITUTES
}

\begin{abstract}
The study of the internationalization of organizations emerges from the interaction and exchange process between organizations of different countries. However, until now the study of this process has focused on commercial and industrial organizations. With this in mind, this study had as a main objective the desire to research the activities of the internationalization of the technological research institutes. The research was carried out primarily through the use of qualitative methodology in the form of multiple case studies, accomplished at three technological research institutes: "Instituto Brasileiro de Tecnologia do Couro, Calçado e Artefatos" - IBTeC (the Brasilian Technological Institute of Leather, Shoes and Manufactured Products), "Instituto de Tecnologia para o Desenvolvimento" - LACTEC (the Technological Institute for Development) and the "Instituto de Pesquisa Tecnológica do Estado de São Paulo" - IPT® (Institute of Technological Research of the State of Sao Paulo). This study was executed by means of semi-structured interviews of both institute directors and researchers, historical document research which included among others the institutions' marketing materials, management reports, and project reports, as well as direct nonparticipant observation made at their facilities. The study's results suggest that the researchers at the technological research institutes are the primary conduits of internationalization. The main targets of international performance are foreign researchers and foreign technological research institutions. The results also suggest a variety of international activities carried out, however, these activities were identified as "low intensity" in the general context of activities developed by technological research institutes.
\end{abstract}

Keywords: Technological Research Institutes; Internationalization; Internationalization Activities; Internationalization Results.

\section{INTRODUÇÃO}

A importância da internacionalização das organizações tem sido reconhecida mundialmente nos últimos 50 anos pelos diversos estudos desenvolvidos na área (VERNON, 1966; HYMER, 1976; JOHANSON; VAHLNE, 1977; RUGMAN, 1978; VERNON, 1979; DUNNING, 1988; BUCKLEY; CASSON, 1993; MCDOUGALL et al., 1994; SULLIVAN, 1994; ANDERSSON, 2000; KOGUT, 2002; TEECE, 2006). A internacionalização tem sido adotada pelas organizações como meio de ampliar mercados, clientes e faturamento, incrementar a lucratividade, aumentar a competitividade e a sobrevivência nos mercados em que atuam. Nas últimas décadas observou-se a intensificação de diferentes formas de atuação das organizações e uma diversificação de áreas, setores e organizações que atuam em outros países, abrindo um amplo campo de estudo sobre a internacionalização das organizações.

Os principais estudos da área nas últimas décadas têm foco na dinâmica de internacionalização das empresas comerciais e industriais, em distintos contextos: 
Internacionalização dos institutos de pesquisas tecnológicas

multinacionais, micro e pequenas empresas, serviços, setores diferenciados e regiões. A abertura dos mercados nacionais, que no Brasil ocorreu na década de 90, e a crescente internacionalização da Pesquisa e Desenvolvimento - P\&D (OECD, 2006) e do Sistema Nacional de Inovação - SNI - dos países (CARLSSON, 2006), contribuiu para que os Institutos de Pesquisas Tecnológicas (IPTs) também atuassem no contexto internacional.

Os Institutos de Pesquisas Tecnológicas - IPTs - são organizações que têm como principal foco a realização de P\&D em conjunto com os vários atores do Sistema Nacional de Inovação - SNI -, contribuindo amplamente para o desenvolvimento do conhecimento científico e tecnológico dos países. Vários IPTs têm buscado desenvolver um novo padrão de atuação, assumindo critérios de desempenho de natureza econômica, privilegiando as atividades de pesquisa mais aplicada, adotando novas formas de relacionamento com governo, agências de fomento, fornecedores, parceiros e clientes, a fim de ampliarem o escopo de atuação, sustentarem-se consistentemente e acompanharem o desenvolvimento da P\&D nacional e internacional (MACULAN; ZOUAIN, 1997; SALLES-FILHO, 2000; SALLESFILHO; BONACELLI, 2005b; OECD, 2006).

Considerando o quadro situacional acima comentado, este estudo visou analisar o grau de internacionalização dos três IPTs estudados. Para tal foram descritas e avaliadas as atividades de internacionalização, os motivos que levaram à busca da internacionalização, as estratégias adotadas e as barreiras encontradas.

\section{REFERENCIAL TEÓRICO}

\subsection{Internacionalização}

O comércio exterior sempre foi visto como o fluxo de trocas comerciais de compra e venda de mercadorias e serviços que ocorriam entre os países. Foi a partir da década de 1960 que as organizações e os processos internacionais relacionados à organização foram incluídos nos estudos desses fluxos de internacionalização (PARKER, 1999). A partir de então, vários estudos foram desenvolvidos com o intuito de explicar o fenômeno da internacionalização das organizações. Embora nenhuma das teorias desenvolvidas consiga explicar a internacionalização como um todo, em seu conjunto trazem importantes contribuições e formam um amplo corpo teórico sobre o tema.

Os conceitos de internacionalização enfatizam os tipos de possíveis interações que uma organização pode ter com o exterior. Para Welch e Loustarinen (1988), a internacionalização é o processo de envolvimento em operações internacionais. Johanson e 
Fabiano Manfio \& João Carlos da Cunha

Vahlne (1977) consideram a internacionalização como um processo gradual de aquisição, integração e uso do conhecimento sobre operações e mercados internacionais, que gradualmente aumentam o compromisso e o envolvimento com os mercados internacionais. Para Kogut (2002), a internacionalização constitui as atividades internacionais das empresas e as interações com os agentes externos, a qual busca responder não apenas às questões do por que as empresas cruzam a fronteira de seu país, mas também como elas fazem isso. Kogut (2002) destaca ainda que a globalização dos mercados e as rápidas mudanças nas economias e nos sistemas políticos forçaram uma nova análise para o sentido da localização, das vantagens competitivas e da transmissão de conhecimento entre os países.

O campo de estudo da internacionalização tem forte origem no estudo da economia internacional (MELIN, 1992), incluindo um vasto campo de teorias no comércio internacional em que o objeto de estudo procura explicar os padrões de investimento no exterior pela variável econômica. Assim, autores como Dunning (1988) e Buckley e Casson (1993), defendem a ideia de que a internacionalização ocorre quando a empresa reúne uma série de vantagens, que torna o investimento no mercado externo financeiramente viável.

As seguidas revisões da literatura acabaram por agrupar em duas abordagens principais as teorias de internacionalização: abordagem econômica e abordagem comportamental.

Na abordagem econômica (HYMER, 1976; RUGMAN, 1978; VERNON, 1979; DUNNING, 1988; BUCKLEY; CASSON, 1979; 1998; DUNNING, 2000; 2001), o foco são as estratégias diretas de atuação no exterior, a fim de aproveitar as vantagens inerentes da organização e da atuação direta no país estrangeiro, buscando contemplar uma ação mais racional e objetiva da decisão de internacionalização.

Por outro lado, a abordagem comportamental (JOHANSON; WIEDERSHEIM-PAUL, 1975; JOHANSON; VAHLNE, 1977; ANDERSSON, 2000; MCDOUGALL; OVIATT, 2000; 2005; SOLBERG; DURRIEU, 2006) enfatiza as estratégias, considerando as atitudes, percepções e comportamento dos tomadores de decisão, os quais adquirem experiência e conhecimento dos mercados internacionais em que atuam e passam a expandir sua atuação para novos mercados culturalmente próximos e de forma gradual.

\subsubsection{Estratégias de inserção internacional}

As estratégias de inserção internacional constituem o modo como as organizações atuam no mercado internacional, revelando as atividades internacionais desenvolvidas pelas organizações. Andersson e Gatignon (1986) destacam que os modos de internacionalização 
Internacionalização dos institutos de pesquisas tecnológicas

diferem em suas relações de custo-benefício, assim, as organizações que buscam desenvolver uma função de negócios internacionais devem escolher o modo de atuação mais adequado ao mercado externo dentro da sua realidade. Contudo várias pesquisas sobre como as organizações realmente tomam a decisão do modo de atuação no mercado externo indicam que poucas organizações tomam decisões conscientes, deliberadas e com uma análise de custo-benefício das suas ações (ANDERSON; GATIGNON, 1986).

Johanson e Vahlne (1977) consideram que as empresas que iniciam suas atividades internacionais através de exportação via agente no exterior, em seguida utilizam escritórios comerciais próprios, e operações de investimento direto no exterior, à medida que se tornam mais experientes ou com maior conhecimento sobre outros mercados.

A abordagem econômica que segue a lógica não linear de entrada no mercado externo apresenta formas alternativas de entrada considerando o Investimento Direto Estrangeiro IDE. Buckley e Casson (1998) citam como modos de internacionalização o licenciamento, franquia, subcontratação, fusões, aquisições, joint ventures, cooperação e novos empreendimentos.

De forma mais sistematizada, Andersson e Gatignon (1986) apresentam os modos de entrada em mercados externos conforme o nível de controle de cada um:

a) tipo alto nível de controle: subsidiária própria e acionista majoritário;

b) tipo médio nível de controle: pluralidade acionária; sociedade meio a meio (50\%); contrato de joint venture; contrato de gerenciamento; contrato de exclusividade restritiva (ex.: licenciamento e acordo de distribuição); franquia; contrato de não exclusividade restritiva e contrato de exclusividade não restritiva;

c) tipo baixo nível de controle: contratos não exclusivos e contratos não restritivos; pequeno acionista.

Os modos de entrada apresentados por Root (1994) englobam três categorias:

a) Exportação - constitui o modo de entrada da empresa no mercado externo quando os produtos são produzidos no país de origem, vendidos e transportados ao mercado de destino. A exportação, segundo Root (1994), ocorre de duas formas: indireta e direta. Na exportação indireta a empresa utiliza um intermediário no próprio país de origem, enquanto na exportação direta, a empresa não utiliza intermediário no país de origem, embora possa adotar um intermediário no exterior.

b) Contrato - constitui o modo de entrada para regular a transferência de tecnologia e habilidades, criando oportunidades de exportação. São associações e acordos contratuais entre 
duas empresas de países diferentes, envolvendo a transferência de uma tecnologia ou de habilidades de uma para a outra.

c) Investimento - constitui o modo de entrada onde a empresa investe diretamente no país estrangeiro, através de escritórios comerciais, armazéns de distribuição e subsidiárias de produção.

Considerando de forma mais ampla, Welch e Loustarinen (1993) e Toyne (1989), consideram a internacionalização como os processos de trocas internacionais, envolvendo todos os aspectos das atividades de negócios internacionais de uma organização. Os autores caracterizam os modos de internacionalização em dois tipos diferentes de atividades: inward atividades de entradas - e outward - atividades de saídas - (WELCH; LUOSTARINEN, 1993). Welch e Loustarinen (1993), destacam ainda que as atividades inward e outward podem apresentar relações entre elas, podendo estas ser relações diretas ou indiretas. As relações diretas ocorrem quando uma influencia diretamente a outra, enquanto as relações indiretas ocorrem quando não há qualquer influência direta no momento em que ocorre a ação. Contudo podem ser aproveitados os resultados de uma ação (inward) para o desenvolvimento de outra ação posterior (outward), sem que se tenha previsto uma relação entre as duas.

\subsubsection{Institutos de Pesquisas Tecnológicas}

Os Institutos de Pesquisas Tecnológicas (IPTs) caracterizam-se por instituições que realizam Pesquisa e Desenvolvimento $(\mathrm{P} \& \mathrm{D})$ de produtos e processos, buscando a inovação. Atuam na fronteira do conhecimento, como principais agentes do desenvolvimento tecnológico dos países, cabendo a eles a geração de conhecimento estratégico; a execução de políticas públicas; a geração de oportunidades de desenvolvimento social e ambiental; e arbitragem (SALLES-FILHO, 2000; SCHNEIDER, 2000).

A importância da atuação internacional nos IPTs é destacada por alguns autores (IMBERT; CHARLES, 2000; SALLES-FILHO; BONACELLI, 2005a; 2005b; WAITRO, 2008), contudo o estudo da internacionalização dessas organizações é uma lacuna ainda pouco explorada. Como base de estudo para a compreensão da internacionalização dos IPTs, analisase o processo de internacionalização das universidades, no qual Morosini (2006, p.108), em seu estudo do estado da arte sobre internacionalização da educação superior, destaca que baseado na natureza produtora do conhecimento, as universidades sempre tiveram na pesquisa a internacionalização de suas atividades, principalmente no caráter autônomo do professorpesquisador (MOROSINI, 2006). 
Internacionalização dos institutos de pesquisas tecnológicas

As principais ações que caracterizam a internacionalização das universidades identificadas por Morosini (2006) foram: intercâmbio de estudantes (presença de estudantes estrangeiros e envio de estudantes para outros países); intercâmbio de professores (presença de professores estrangeiros e envio de professores para outros países); contato com estudantes e professores internacionais; pesquisa internacional; cooperações internacionais; redes de pesquisa; associações internacionais envolvendo consultoria para universidades estrangeiras e outras instituições; existência de departamentos ou setores destinados à administração das atividades internacionais; currículos internacionalizados; cursos para executivos de negócios no âmbito internacional; exportação de MBAs; estabelecimento via internet, de campi em outros países; estabelecimento de campi físicos em outros países; cursos de treinamento em outros países; relações universitárias com outros países.

Outros três estudos apresentam a internacionalização das Universidades: Miura (2006), que pesquisou a internacionalização da Universidade de São Paulo - USP -, Stallivieri (2005), com o estudo das estratégias de internacionalização da Universidade de Caxias do Sul - UCS -, e Costa (2008), que analisou a participação de empresas nas 20 maiores instituições de ensino privadas do país. Miura (2006) analisou que as universidades focam suas ações de internacionalização em duas grandes dimensões: parcerias internacionais e ensino. As parcerias internacionais compreendem acordos institucionais e intercâmbio de estudantes e professores, enquanto o ensino engloba o conteúdo internacional de disciplinas e o ensino de língua estrangeira.

Stallivieri (2005) identificou que a UCS possuiu um departamento específico para a coordenação da área internacional e que as ações de internacionalização da UCS são:

a) inserção em redes de cooperação internacional;

b) participação em diferentes programas de mobilidade acadêmica internacional estudantes, professores e investigadores;

c) programas de investigação conjunta favorecendo a qualificação dos programas institucionais;

d) acordos bilaterais de cooperação acadêmica, científica, técnica, didática e cultural;

e) publicações em conjunto com instituições estrangeiras.

Costa (2008) aponta que das instituições pesquisadas algumas já possuem participação de empresas de capital aberto, atuando na viabilização da entrada de capital estrangeiro para fomento das atividades das universidades, o que representa uma modalidade de interação internacional bastante envolvente. 
Observa-se nos estudos relatados que as universidades estão passando por um processo de internacionalização em que podem destacar-se oito fatores como as principais ações e estratégias desenvolvidas:

1) intercâmbios (professores, pesquisadores e estudantes);

2) cooperações de ensino e pesquisa;

3) participação em redes;

4) participação em associações;

5) publicações em conjunto com estrangeiros;

6) estabelecimento de departamento internacional;

7) estabelecimento de campi no exterior;

8) captação de recursos estrangeiros.

Considerando o quadro teórico apresentado, com distintas teorias de internacionalização, as ações e estratégias desenvolvidas pelas universidades no Brasil no processo de internacionalização, as quais se assemelham à característica das organizações pesquisadas, o quadro teórico adotado para a realização da pesquisa concentra-se nos princípios empregados por Welch e Loustarinen (1988), que consideram a internacionalização como um processo de envolvimento em operações internacionais, que amplia a gama de atividades pesquisadas no estudo da internacionalização dos IPTs.

$\mathrm{Na}$ operacionalização desta pesquisa, o conceito das atividades de internacionalização inward e outward (WELCH; LUOSTARINEN, 1993) é aplicado para caracterizar os tipos de atividades internacionais realizadas pelos IPTs, conforme anexo A.

\section{METODOLOGIA}

A investigação utilizou a pesquisa qualitativa, com método de estudo de casos múltiplos (YIN, 2005). Do ponto de vista teórico, o estudo de caso foi a estratégia escolhida pelo fato de que os resultados obtidos neste tipo de investigação são considerados mais convincentes, dando maior robustez à pesquisa exploratório-descritiva (NEUMAN, 2002).

A análise compreendeu o estudo da dinâmica das atividades internacionais de três Instituições: Instituto Brasileiro de Tecnologia do Couro, Calçado e Artefatos - IBTeC -, Instituto de Tecnologia para o Desenvolvimento - LACTEC -, e Instituto de Pesquisa Tecnológica do Estado de São Paulo - IPT ${ }^{\varpi}$. A escolha das organizações foi intencional, tendo como critérios não apenas o acesso, mas também as características de cada instituição, como a constituição jurídica, tamanho, áreas de atuação e relevância para o setor de atuação. 
Internacionalização dos institutos de pesquisas tecnológicas

Foram obtidos depoimentos em entrevistas orientadas por um roteiro semiestruturado com questões qualitativas. Estas informações receberam um tratamento qualitativo por intermédio da análise de conteúdo, baseada numa análise temática e interpretativa a luz dos conceitos referenciados na análise teórica. Foram realizadas quatro entrevistas em cada Instituição, totalizando 12 entrevistas, conforme quadro abaixo:

Quadro 1 - Entrevistas realizadas na pesquisa de campo.

\begin{tabular}{|l|c|l|}
\hline \multicolumn{1}{|c|}{ Caso } & $\begin{array}{l}\text { Quantidade } \\
\text { Entrevistas }\end{array}$ & \multicolumn{1}{c|}{ Entrevistados } \\
\hline IBTeC & 4 & $\begin{array}{l}\text { - Vice-Presidente de Relações Institucionais } \\
\text { - Diretora Técnica } \\
\text { - Pesquisador 1 - Área da Biomecânica } \\
\text { - Pesquisador 2 - Área de Controle da Qualidade }\end{array}$ \\
\hline LACTEC & 4 & $\begin{array}{l}\text { - Diretor de Operações Tecnológicas } \\
\text { - Diretor de Desenvolvimento Tecnológico } \\
\text { - Pesquisador 1 - Área de Tecnologia em Materiais } \\
\text { - Pesquisador 2 - Área de Eletrônica }\end{array}$ \\
\hline IPT & & $\begin{array}{l}\text { - Diretor Adjunto } \\
\text { - Assessor de Cooperações Internacionais } \\
\text { - Pesquisador 1 - Área de Redes de Segurança Digital } \\
\text { - Pesquisador 2 - Área Recursos Hídricos e Avaliação Geoambiental }\end{array}$ \\
\hline
\end{tabular}
Fonte: elaborado pelo autor.

Para as entrevistas foram selecionados, em cada Instituto, dois dirigentes da área administrativa, que responderam a questões sobre as estratégias gerais de atuação, estratégias de internacionalização e resultados da internacionalização do Instituto. Foram entrevistados também dois pesquisadores com experiência no envolvimento em projetos internacionais, os quais responderam a questões sobre o envolvimento dos pesquisadores nas ações internacionais e os resultados dessas ações para o Instituto. As entrevistas foram gravadas e posteriormente transcritas para realização da análise.

Além das entrevistas, e com o intuito de pesquisar outras fontes de evidências, foram também analisados documentos disponibilizados pelas Instituições, tais como relatórios anuais dos institutos, informes técnicos de pesquisa, material de divulgação nacional e internacional e o próprio site dos institutos. Esta decisão segue a sugestão de Weiss (1994), que assinala a importância da triangulação de dados no intuito da integração de perspectivas e maior confiabilidade das análises. 


\section{DESCRIÇÃO DOS CASOS}

\subsection{Instituto Brasileiro de Tecnologia do Couro, Calçado e Artefatos - IBTeC}

O Instituto Brasileiro de Tecnologia do Couro, Calçado e Artefatos - IBTeC constitui-se como uma entidade de direito privado, sem fins lucrativos e objetivos de gerar pesquisas no setor de calçados, desenvolvendo novas tecnologias e atuando no controle da qualidade dos calçados e artefatos, além de buscar auxiliar a eficácia coletiva do sistema calçadista.

O IBTeC foi fundado em 1972 por um grupo de empresários que buscava apoio técnico para as suas ações no mercado interno e externo, com o nome de Instituto Brasileiro de Couro e Afins - IBCA -, atuou por alguns anos como um núcleo do sistema da Federação das Indústrias do Rio Grande do Sul - FIERGS. Em 1976, o instituto passou a ser uma entidade independente atuando com o nome de Centro Tecnológico do Couro, Calçados e Afins - CTCCA. Em 2005, buscando maior reconhecimento junto aos organismos nacionais e internacionais o nome foi novamente alterado, agora para Instituto Brasileiro de Tecnologia do Couro, Calçado e Artefatos - IBTeC.

O Instituto está subdividido em núcleos de competências: Núcleo de Biomecânica, Núcleo de Controle de Qualidade, Núcleo de Relacionamento com o Mercado e o Núcleo Administrativo Financeiro. O quadro funcional atual do IBTeC conta com 39 funcionários. Desse número, $50 \%$ trabalham no administrativo, $25 \%$ no parte técnica e $25 \%$ na pesquisa. A diretoria, que não compõe o quadro funcional do Instituto, é composta por associados do Instituto sem vínculo empregatício, exceto pelo presidente. Assim, a diretoria compreende o presidente, o vice-presidente de Relações Institucionais e 15 Conselhos Técnicos com um vice-presidente e um diretor em cada conselho. As 15 áreas de atuação são: relações institucionais; couro, calçado, componentes, máquinas, meio ambiente, ensino, serviços, recursos humanos e ação social, moda e design, lojistas, inovação tecnológica, artefatos de couro e artigos de viagem, associado, jurídico e vestuário.

\subsection{Instituto de Tecnologia para o Desenvolvimento - LACTEC}

O Instituto de Tecnologia para o Desenvolvimento - LACTEC - constitui-se como um centro de pesquisa tecnológica, sem fins lucrativos, autossustentável, que emprega como objetivo buscar através de soluções tecnológicas, contribuir e promover o desenvolvimento econômico, científico e social, com responsabilidade ambiental. O LACTEC está localizado 
na cidade de Curitiba/PR, tem atuação nacional e recebeu nos últimos anos inúmeros prêmios nacionais por sua excelência científica (LACTEC, 2008).

O LACTEC foi fundado em 1997, quando passou a coordenar a captação de recursos, vendas de serviços e parcerias do Laboratório Central de Pesquisa e Desenvolvimento - LAC - (1982), até então mantido pelo convênio entre a Universidade Federal do Paraná - UFPR - e a Companhia Paranaense de Energia - COPEL. Em 1999, o LACTEC se tornou centro de pesquisa independente, assumindo as operações do LAC. Em 2000, o LACTEC fundou o Laboratório de Emissões Veiculares - LEME- e assumiu também as operações do Laboratório de Materiais e Estruturas - LAME (1994) e do Centro de Hidráulica e Hidrologia Prof. Parigot de Souza - CEHPAR (1959) -, que também eram mantidos por convênios entre a UFPR e a COPEL. Assim, o LACTEC formou o seu quadro laboratorial:

$>$ LAC - Laboratório Central de Pesquisa e Desenvolvimento - Integra laboratórios de eletricidade, eletrônica, materiais, meio ambiente, mecânica e química aplicada.

LEME - Laboratório de Emissões Veiculares - Integra os laboratórios de mecânica e emissões veiculares.

$>$ CHEPAR - Centro de Hidráulica e Hidrologia Prof. Parigot de Souza - Integra os laboratórios de hidráulica, hidrologia, recursos ambientais e geoprocessamento.

LAME - Laboratório de Materiais e Estruturas - Integra os laboratórios de estruturas civis, concreto e solos.

O quadro funcional atual do LACTEC conta com 385 funcionários, mais 213 temporários (bolsistas e estagiários) e ainda 26 consultores técnicos externos.

\subsection{Instituto de Pesquisas Tecnológicas do Estado de São Paulo - IPT}

O Instituto de Pesquisas Tecnológicas do Estado de São Paulo - IPT ${ }^{\varpi}$ - tem por objetivo atender à demanda de ciência e tecnologia nas diversas áreas da Engenharia em que atua. Iniciou suas atividades em 1899 como Gabinete de Resistência dos Materiais, com a finalidade de dar suporte a Escola Politécnica de São Paulo e passou a ser reconhecido como Instituto de Pesquisa Tecnológica - IPT ${ }^{\varpi}$ - em 1934. O IPT ${ }^{\varpi}$, desde 1976, constitui-se como uma empresa pública, com a figura jurídica de sociedade anônima, vinculado à Secretaria de Desenvolvimento do Governo do Estado de São Paulo.

Sua sede principal está localizada na cidade de São Paulo, dentro do complexo da Cidade Universitária, tendo ainda unidades em Guarulhos/SP e Franca/SP, totalizando uma infraestrutura de $96.500 \mathrm{~m}^{2}$ de área construída, distribuídos em 13 centros, 30 laboratórios e 10 seções técnicas. As atividades desenvolvidas pelo IPT ${ }^{\boxplus}$ abrangem 12 grandes áreas, as 
quais compõem os centros de atuação do Instituto e dois núcleos de atendimento: Engenharia Naval e Oceânica; Integridade de Estruturas e Equipamentos; Metrologia de Fluidos; Metrologia em Química; Metrologia Mecânica e Elétrica; Tecnologia da Informação, Automação e Mobilidade; Tecnologia de Obras de Infraestrutura; Tecnologia de Processos e Produtos; Tecnologia de Recursos Florestais; Tecnologias Ambientais e Energéticas; Tecnológico da Indústria da Moda; Tecnológico do Ambiente Construído; Atendimento Tecnológico à Micro e Pequena Empresa; e Economia e Administração de Tecnologia.

O quadro funcional do IPT ${ }^{\circledR}$ conta com 1.306 funcionários e mais 186 temporários. Desse número, $40 \%$ trabalham na pesquisa, $30 \%$ no apoio técnico, $5 \%$ no apoio operacional e $25 \%$ no apoio administrativo.

\section{ANÁLISE DOS DADOS}

\subsection{Internacionalização}

$\mathrm{Na}$ análise da internacionalização dos IPTs pesquisados, constata-se que IBTeC e IPT ${ }^{\varpi}$ têm uma atuação mais forte através de seus pesquisadores e que o LACTEC tem atuado mais institucionalmente. IBTeC e LACTEC atuam mais espontaneamente, sem um planejamento prévio das ações internacionais a serem desenvolvidas. Já o IPT ${ }^{\varpi}$, embora recentemente, deu início à implementação do planejamento de suas ações internacionais.

Historicamente, o IPT ${ }^{\varpi}$ tem uma atuação internacional muito mais forte que IBTeC e LACTEC. Contudo, as ações do IPT ${ }^{\circledR}$ nos anos 70 e 80, se caracterizam como ações inward, e que praticamente cessaram nos anos 90 e 2000, retornando recentemente com ações inward e outward. O LACTEC, com apenas 10 anos de idade, nunca teve uma atuação internacional contundente, mas sempre manteve parcerias, contatos e intercâmbios internacionais, que atualmente entra em foco ao ser especificado como um dos objetivos do planejamento estratégico. Diferentemente, o IBTeC nasceu para desenvolver uma ação internacional indireta e até hoje é uma das principais ações do Instituto, promovendo desdobramentos para novas ações. Concomitantemente à criação de uma linha de pesquisa na área de Biomecânica desenvolveu uma forte rede de contatos entre os pesquisadores e atualmente representa a ação de maior prospecção internacional do Instituto.

O quadro abaixo apresenta um comparativo das principais atividades internacionais dos IPTs pesquisados em ações outward: 
Internacionalização dos institutos de pesquisas tecnológicas

Quadro 2 - Comparativo das Atividades de Internacionalização - Outward

\begin{tabular}{|c|c|c|c|c|c|c|c|c|c|}
\hline \multirow{3}{*}{ Outward - Saída } & \multicolumn{9}{|c|}{ 2003-2008 Realizou: } \\
\hline & \multicolumn{3}{|c|}{ IBTeC } & \multicolumn{3}{|c|}{ LACTEC } & \multicolumn{3}{|c|}{ IPT $^{\circledR}$} \\
\hline & REC* & $\mathbf{C O N}_{* *}$ & ESP**** & REC* & CON** & ESP**** & REC* & CON** & ESP*** \\
\hline \multicolumn{10}{|l|}{ Interação } \\
\hline Visita à organização do mesmo ramo no exterior & & & $\mathbf{X}$ & & $\mathbf{X}$ & & $\mathbf{X}$ & & \\
\hline Participação em rodadas de negócio internacional & & & $\mathbf{X}$ & & & $\mathbf{X}$ & & & $\mathbf{X}$ \\
\hline Participação de licitações internacionais & & & & & & & & $\mathbf{X}$ & \\
\hline \multicolumn{10}{|l|}{ Cooperação } \\
\hline $\begin{array}{l}\text { Cooperação ou convênios com universidade } \\
\text { estrangeira }\end{array}$ & & $\mathbf{X}$ & & & $\mathbf{X}$ & & & $\mathbf{X}$ & \\
\hline Cooperação ou convênios com IPTs estrangeiros & & $\mathbf{X}$ & & & $\mathbf{X}$ & & & $\mathbf{X}$ & \\
\hline \multicolumn{10}{|l|}{ Comercialização de Serviços } \\
\hline $\begin{array}{l}\text { Envio de pesquisadores brasileiros para realizar } \\
\text { serviços no exterior }\end{array}$ & & & $\mathbf{X}$ & & & $\mathbf{X}$ & $\mathbf{X}$ & & \\
\hline Prestação de consultoria no exterior & & & $\mathbf{X}$ & $\mathbf{X}$ & & & $\mathbf{X}$ & & \\
\hline $\begin{array}{l}\text { Serviços de P\&D foram contratados por empresa } \\
\text { estrangeira no Brasil }\end{array}$ & & & & & $\mathbf{X}$ & & $\mathbf{X}$ & & \\
\hline Prestação serviços técnicos p/ empresa no exterior & & & $\mathbf{X}$ & & & $\mathbf{X}$ & & $\mathbf{X}$ & \\
\hline $\begin{array}{l}\text { Cooperação com empresas multinacionais no } \\
\text { Brasil para desenvolvimento de produtos }\end{array}$ & & $\mathbf{X}$ & & & $\mathbf{X}$ & & & & \\
\hline Desenvolvimento de $\mathrm{P} \& \mathrm{D} \mathrm{p} /$ empresa no exterior & & & & & & & & $\mathbf{X}$ & \\
\hline Licenciamento de tecnologia $\mathrm{p} /$ firma no exterior & & & & & & & $\mathbf{X}$ & & \\
\hline $\begin{array}{l}\text { Realização de ensaios técnicos em produtos que se } \\
\text { destinam ao mercado internacional }\end{array}$ & & $\mathbf{X}$ & & & & & & & \\
\hline \multicolumn{10}{|l|}{ Outros } \\
\hline $\begin{array}{l}\text { Editoração de revista técnica - língua estrangeira - } \\
\text { e distribuição no exterior }\end{array}$ & $\mathbf{X}$ & & & & & & & & \\
\hline
\end{tabular}

Fonte: Dados da pesquisa.

*** REC: Recentemente - Representa uma atividade internacional realizada recentemente 2007-2008.

*** CON: Constantemente - Representa uma atividade internacional constante, que se realizou ou afetou a empresa por mais de 2 anos.

*** ESP: Esporadicamente - Representa uma atividade internacional esporádica, que se realizou poucas vezes nesse período.

O comparativo das atividades de internacionalização outward dos IPTs pesquisados demonstra que o IBTeC tem uma interação internacional esporádica, com ocasionais visitas a universidades e IPTs estrangeiros e baixa participação em reuniões de negócios internacionais, conforme relatado pelo vice-presidente do Instituto:

Essas ações são sempre participações pontuais a convite de congressos ou dos outros centros do mundo similares ao nosso. E similares ao centro daqui existem nos principais países do mundo, existe na Argentina, no México, na Colômbia, existem vários na Europa, existe no Oriente. Então, nós temos, [...], viagens ou intercâmbios muito pontuais em cima desses eventos. 
O LACTEC mantém-se constantemente visitando outros IPTs. Já o IPT ${ }^{\oplus}$ destaca-se pela recente retomada das visitas a outros IPTs e a constante participação em licitações internacionais. Embora LACTEC e IPT ${ }^{\circledR}$ tenham apontado a constante interatividade internacional, o IPT ${ }^{\varpi}$ é muito mais ativo nessas ações do que o LACTEC. O IPT $^{\varpi}$ caracterizase por incentivar seus pesquisadores e dispor de recursos para essa interação, principalmente a visita às organizações internacionais, situação que não ocorre com os outros dois Institutos, que se dispõem a realizar essas atividades, mas enfrentam dificuldades financeiras para realizá-las mais constantemente.

Dois fatores são identificados para a maior interação do IPT ${ }^{\circledR}$ : a) a instituição ser pública, o que proporciona um recurso específico para investimentos, e b) o planejamento e maior comprometimento com esse tipo de ação. Esses fatores não são encontrados no IBTeC e LACTEC e dificultam as ações de interação por parte dos Institutos.

As ações de convênios e cooperações com outros IPTs e universidades internacionais são consideradas uma ação consolidada e constante para os IPTs pesquisados (representam a principal ação institucional internacional dos Institutos).

No IBTeC destaca-se o convênio com a SATRA, que certifica os ensaios realizados pelo Instituto, conforme descrito pelo seu Vice-Presidente:

A SATRA certifica os nossos ensaios, então com esse [parceiro] existe uma interação muito forte. Essa talvez seja a ação mais forte no momento, permanente de relacionamento internacional, é esse convênio.

O Diretor de Desenvolvimento Tecnológico do LACTEC destaca a forma como as parcerias entre as instituições ocorrem:

As parcerias se formam através de contatos, o pessoal foi pra lá, ou o que acontece às vezes mais dos Institutos ou Universidades do exterior vir pra cá. Nós tivemos, por exemplo, ontem uns espanhóis e na sexta-feira nós tivemos uns franceses que nos procuraram para fazer alguma coisa em conjunto. Um projeto de parceria em conjunto. Então isso é uma mão de duas vias nós vamos, mas acho que mais eles vêm pra cá.

$\mathrm{O}_{\text {IPT }}{ }^{\circledR}$ institucionalmente tem desenvolvido uma série de parcerias internacionais na

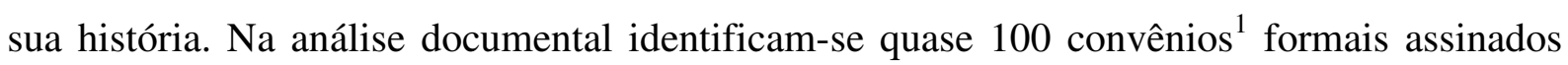
nos últimos 50 anos da Instituição.

Esse tipo de ação assemelha-se muito com o que é desenvolvido na internacionalização das universidades, conforme foi levantado por Morosini (2006), dado o caráter das instituições trabalharem com "conhecimento" e o seu desenvolvimento ocorrer

\footnotetext{
${ }^{1}$ Acordo de Cooperações, Carta/Protocolo de Intenções e Protocolo Adicional/Termo Aditivo
} 
especialmente no compartilhamento do "conhecimento". Portanto esse tipo de ação ganha relevância frente às outras ações devido à busca por instituições que compartilhem conhecimentos para a evolução da P\&D.

Na comercialização de serviços, o IBTeC destaca-se por manter ações constantes de cooperação com empresas multinacionais no Brasil para o desenvolvimento de produtos e a realização de ensaios técnicos em produtos a serem exportados. A pesquisadora da área de Controle da Qualidade expõe o envolvimento internacional dessas duas ações:

Nós realizamos hoje dentro da área de Controle da Qualidade a certificação de produtos. O que é a certificação de produtos: a gente ensaia o produto, e manda os relatórios a nível internacional, então é esse o foco, diferente da biomecânica que a internacionalização é mais uma questão de desenvolvimento de tecnologia, então são duas coisas bastante diferentes, mas são importantes. [...] A gente hoje trabalha com produtos que vão para o exterior e são utilizados em consumidores internacionais e nós [IBTeC] estamos garantindo a qualidade daquele produto, nós [IBTeC] estamos avaliando aquele produto para o futuro consumidor no exterior.

Esporadicamente, o Instituto presta serviços técnicos e de consultoria no exterior. Isso demonstra que as ações de comercialização de serviços internacionais do IBTeC ocorre principalmente de forma indireta.

O LACTEC igualmente demonstra que suas ações de comercialização de serviços internacionais ocorrem de forma indireta através de terceiros, realizando constantemente serviços de $\mathrm{P} \& \mathrm{D}$ para empresas estrangeiras que vêm ao Brasil e cooperações com empresas multinacionais estabelecidas no Brasil. As ações no exterior ocorrem esporadicamente e através de empresas brasileiras ou governamentais que vão atuar no exterior, conforme relato dos entrevistados do Instituto.

A experiência internacional que eu tenho representando o instituto ou pelo menos em alguma atividade ligada ao instituto, basicamente, a grande experiência que eu tenho é a consultoria que o LACTEC deu ao Ministério de Minas e Energia na implantação da parceria internacional pra economia do hidrogênio. [...] Então foram diversas viagens, algumas com um caráter um pouco mais político, mas a grande parte delas com um caráter técnico, quase todas de representação ou participação da delegação brasileira nas atividades. [...] Ele [Ministério de Minas e Energia] precisava de uma assessoria técnica e contratou o LACTEC durante dois anos, 2005 até o final de 2007. (Pesquisador da área de Tecnologia em Materiais).

O LACTEC tem um rool muito interessante, nós já tivemos aqui fazendo estudos na Malásia, agora temos um estudo na República Dominicana, [...] já fizemos na China, na Malásia, Seul, agora tem esse pra República Dominicana. Porque o que acontece, são empresas projetistas brasileiras que ganharam um projeto de uma hidrelétrica no exterior, então pra você executar esse projeto, fazer o desenho desse projeto, você precisa ter estudos de assoreamento e uma série de coisas, então nessas áreas o LACTEC é muito forte. O LACTEC é procurado, então isso é desenvolvido, temos que emitir alguns pareceres, relatórios e é entregue para as empresas e isso vai ser levado em consideração nós detalhes do projeto, então o LACTEC é acionado pra trabalhar em conjunto com essas empresas que vão atuar no exterior, nessa área de construção de hidrelétricas. (Diretor de Desenvolvimento Tecnológico). 
O IPT $^{\oplus}$ também se destaca por realizar ações de comercialização de serviços internacionais de forma indireta através de terceiros, conforme foi destacado pelo Diretor Adjunto da Instituição.

[...] Hoje a gente faz alguns ensaios de plataformas de navios que estão sendo construídas fora do país, pra fazer as medições, a metrologia, a aferição da parte vamos dizer assim hidráulica dos navios, porque são plataformas de exploração petrolíferas, de gás também ou transporte de óleo. Então, esses equipamentos dos navios ao invés de receber um navio aqui, fazer a aferição e se tiver problema devolver para o estaleiro pra concertar, um procedimento totalmente desnecessário, o que o pessoal nosso faz, a Petrobrás indica aonde precisamos fazer a aferição, então os técnicos nossos vão pra lá, Coreia, Japão, onde for, fazem os testes, as medidas necessárias, facilitando tanto para o comprador como pra quem fabrica, se tiver que fazer algumas alterações e reparos.

As ações constantes no IPT ${ }^{\boxplus}$ são a prestação de serviços técnicos e o desenvolvimento de $\mathrm{P} \& \mathrm{D}$ no exterior, mas as demais ações são recentes, destacando-se o licenciamento de algumas tecnologias para empresas e governos no exterior, algo que ainda não ocorreu nos outros dois IPTs pesquisados.

Como se pode observar, as principais ações de comercialização dos IPTs pesquisados ocorrem principalmente através de multinacionais que atuam no Brasil ou empresas brasileiras que atuam no exterior e ações governamentais que são realizadas no exterior, estabelecendo-se como ações indiretas. Essa é uma forma proveitosa de atuação internacional dos Institutos, amparando-se em terceiros para ganhar experiência e desenvolver contatos para futuras atuações internacionais, similar a proposta de internacionalização de Johanson e Vahlne (1977) em que as empresas iniciam um processo de internacionalização através de agentes que já atuam no exterior (terceiros), adquirindo conhecimento sobre o mercado e à medida que se tornam mais experientes evoluem para novas formas de atuação nos mercados internacionais de forma independente, direta.

O baixo número de serviços internacionais prestados diretamente tem ligação com o foco de atuação dos Institutos. Na sua essência, a função dos IPTs consiste em desenvolver tecnologias para o desenvolvimento de setores da economia regional e nacional (SALLESFILHO, 2000; SALLES-FILHO; BONACELLI, 2005a), o que provoca uma concentração da atuação dos Institutos no âmbito regional e nacional. Outro fator que contribui para a baixa interação comercial no âmbito internacional é o limitado número de patentes registradas nacionalmente e principalmente internacionalmente.

O registro de patentes funciona não só como uma forma de proteger as inovações desenvolvidas, mas também como divulgador das inovações. Os três IPTs citaram já ter recebido encaminhamento de interessados nas patentes registradas através do Instituto 
Internacionalização dos institutos de pesquisas tecnológicas

Nacional de Propriedade Intelectual - INPI -, contudo o baixo número de patentes registradas ainda limita esse tipo de ação. Destaca-se o IPT ${ }^{\circledR}$ que, através do Programa de Investigação Tecnológica - PIT - (programa desenvolvido pelo Governo do Estado de São Paulo) proporcionou o aumento nas patentes internacionais registradas e colhe resultados com os primeiros licenciamentos de inovações internacionais.

Por fim, identifica-se uma ação isolada e recente do IBTeC, que é a publicação da sua revista em língua estrangeira (espanhol) e distribuída na América Latina, principalmente na Colômbia. Essa ação reflete o interesse do Instituto em estar presente em outros países, constituindo a primeira ação de divulgação e aproximação do Instituto com agentes internacionais na América Latina.

O quadro abaixo apresenta um comparativo das principais atividades internacionais dos IPTs pesquisados em ações inward:

Quadro 3 - Comparativo das Atividades de Internacionalização - Inward

\begin{tabular}{|c|c|c|c|c|c|c|c|c|c|}
\hline \multirow{3}{*}{ Inward - Entrada } & \multicolumn{9}{|c|}{ 2003-2008 Realizou: } \\
\hline & \multicolumn{3}{|c|}{ IBTEC } & \multicolumn{3}{|c|}{ LACTEC } & \multicolumn{3}{|c|}{ IPT $^{\circledR}$} \\
\hline & REC* & $\mathrm{CON}^{* *}$ & ESP $* * * *$ & REC* & CON* $*$ & ESP $* * *$ & REC* & CON** & ESP*** \\
\hline \multicolumn{10}{|l|}{ Interação } \\
\hline Visita à organização do mesmo ramo no exterior & & & $\mathbf{X}$ & & $\mathbf{X}$ & & $\mathbf{X}$ & & \\
\hline Participação de congressos/eventos internacionais & & & & & $\mathbf{X}$ & & & $\mathbf{X}$ & \\
\hline Visita a feiras no exterior & & & & & & $\mathbf{X}$ & $\mathbf{X}$ & & \\
\hline Recebeu Visitas Técnicas Estrangeiras & & & $\mathbf{X}$ & & $\mathbf{X}$ & & & $\mathbf{X}$ & \\
\hline $\begin{array}{l}\text { Intercâmbio de estudantes/pesquisadores do } \\
\text { exterior }\end{array}$ & $\mathbf{X}$ & & & & & $\mathbf{X}$ & & & $\mathbf{X}$ \\
\hline $\begin{array}{l}\text { Recebeu firma ou profissional do exterior para dar } \\
\text { treinamento no Brasil }\end{array}$ & & & & & & $\mathbf{X}$ & & & $\mathbf{X}$ \\
\hline \multicolumn{10}{|l|}{ Qualificação } \\
\hline Participação de congressos/eventos internacionais & & & & & $\mathbf{X}$ & & & $\mathbf{X}$ & \\
\hline $\begin{array}{l}\text { Envio de funcionários/pesquisadores para } \\
\text { treinamento técnico/profissional no exterior }\end{array}$ & & & & & & $\mathbf{X}$ & $\mathbf{X}$ & & \\
\hline $\begin{array}{l}\text { Envio de funcionários/pesquisadores para realizar } \\
\text { mestrado/doutorado no exterior }\end{array}$ & & & & & & $\mathbf{X}$ & & & $\mathbf{X}$ \\
\hline \multicolumn{10}{|l|}{ Cooperação } \\
\hline $\begin{array}{l}\text { Estabeleceu parcerias com } \\
\text { universidades/pesquisadores estrangeiras }\end{array}$ & & $\mathbf{X}$ & & & & $\mathbf{X}$ & & $\mathbf{X}$ & \\
\hline $\begin{array}{l}\text { Estabeleceu cooperação ou convênios com IPTs } \\
\text { estrangeiros }\end{array}$ & & $\mathbf{X}$ & & & & $\mathbf{X}$ & & $\mathbf{X}$ & \\
\hline \multicolumn{10}{|l|}{ Comerciais } \\
\hline $\begin{array}{l}\text { Importação de máquinas e/ou equipamentos } \\
\text { diretamente }\end{array}$ & & & $\mathbf{X}$ & & & $\mathbf{X}$ & $\mathbf{X}$ & & \\
\hline Importação de matéria-prima diretamente & & $\mathbf{X}$ & & & & $\mathbf{X}$ & & & $\mathbf{X}$ \\
\hline
\end{tabular}


Fabiano Manfio \& João Carlos da Cunha

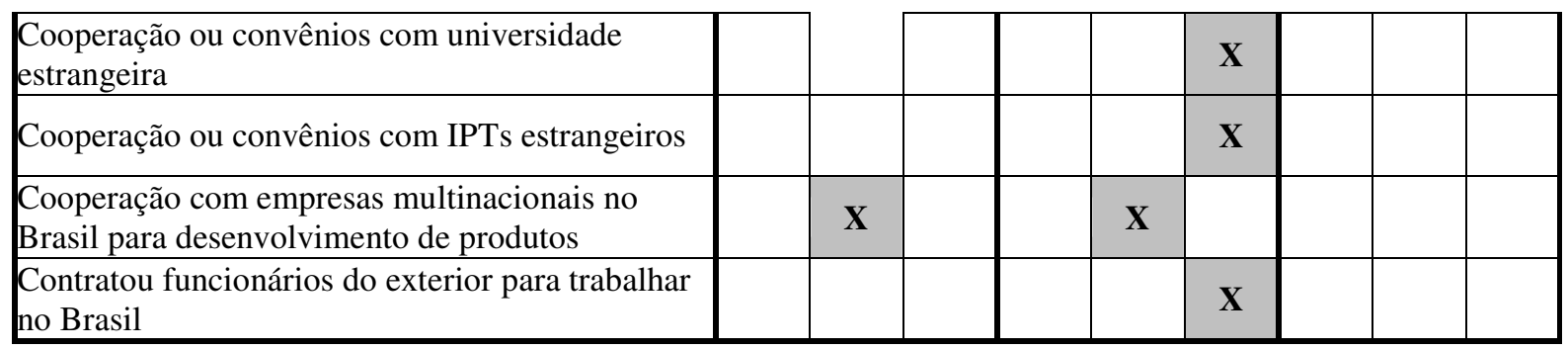

Fonte: Dados da pesquisa.

*** REC: Recentemente - Representa uma atividade internacional realizada recentemente 2007-2008.

*** CON: Constantemente - Representa uma atividade internacional constante, que se realizou ou afetou a empresa por mais de 2 anos.

*** ESP: Esporadicamente - Representa uma atividade internacional esporádica, que se realizou poucas vezes nesse período.

O comparativo das atividades de internacionalização inward dos IPTs pesquisados destaca-se principalmente as ações de interação e cooperação dos IPTs. As atividades internacionais inward de interação são constantemente desenvolvidas pelos IPTs pesquisados, principalmente as ações de visita a universidades e IPTs estrangeiros por parte dos três IPTs, e participação em congressos e eventos internacionais por parte de LACTEC e IPT ${ }^{\circledR}$. Destacamse também as visitas técnicas estrangeiras recebidas por parte dos três IPTs, as quais fazem parte do processo de busca por parcerias e cooperações internacionais.

O intercâmbio de estudantes e pesquisadores do exterior tem ocorrido esporadicamente. No IBTeC identificou-se apenas um caso de intercâmbio recentemente: "Nós começamos muito timidamente com uma bolsista de graduação alemã, ela veio pra cá, fez intercâmbio e ficou seis meses trabalhando aqui comigo na área de Biomecânica" (pesquisador da área de Biomecânica).

No IPT ${ }^{\varpi}$ esse tipo de ação não é uma prática constante devido ao interesse inverso de o Instituto enviar seus pesquisadores para o exterior. No IBTeC e LACTEC, existe maior interesse no recebimento de estudantes e pesquisadores do exterior, contudo a questão financeira é um empecilho para o incremento dessa prática.

A questão da qualificação, a participação em congressos e eventos internacionais tem representado uma das principais ações dos IPTs. No IBTeC não se identificou atividade de qualificação internacional recentemente, mas identificou-se o desenvolvimento e a participação em congressos e eventos nacionais de âmbito internacional, no qual participam muitos agentes internacionais:

Por exemplo, ocorreu nesse ano o VI Congresso Brasileiro de Biometria de Calçado e eles [pesquisadores e professores de outros países] vieram, então nesses dias que eles ficam aqui a gente discute a parte da biometria que a gente tem dúvidas, tem muitas dúvidas sobre isso aí, tanto que o único país do mundo que tem normas de conforto é o Brasil. (pesquisador da área de Biomecânica - IPT ${ }^{\varpi}$ ). 
Internacionalização dos institutos de pesquisas tecnológicas

No LACTEC, apesar de identificar-se com a constante participação em eventos e congressos internacionais, constatam-se dificuldades dos pesquisadores em participarem desse tipo de atividade internacional devido à falta de um plano de atuação internacional. O IPT ${ }^{\circledR}$ é o Instituto com maior destaque nas ações de participação de eventos, congressos, treinamentos e intercâmbios, realizando mais de 200 participações internacionais entre 2004 e Nov/2008. Cabe ainda destacar o planejamento do IPT $^{\varpi}$, que até o ano de 2010, pretende mandar mais de 50 pesquisadores para realizarem treinamentos técnicos e pós-graduação de no mínimo 6 meses no exterior.

A ação de enviar pesquisadores para treinamentos no exterior do IPT $^{\circledR}$ é o reflexo positivo das ações internacionais desenvolvidas nos últimos anos e da percepção dos diretores do Instituto da necessidade de conhecimento das tecnologias que estão sendo desenvolvidas no mundo. Além de almejar que os pesquisadores possam formar uma rede de relacionamentos que venha a contribuir com novas ações internacionais no futuro.

Hoje a grande prioridade do IPT $T^{\oplus}$ na parte internacional é a capacitação de
pesquisadores. A coisa é bastante recente, no ano de 2008 em que foi definida
mesmo essa política de capacitação de pesquisador. Até 2010 são previstas mais ou
menos 50 viagens de pesquisadores do IPT . A ideia é que cada um fique mais ou
menos 6 meses fazendo algum estágio, não precisa ser necessariamente uma pós-
graduação, pode ser na parte técnica em alguma instituição do exterior. E tem a
vantagem também que uma vez que você manda o pesquisador para o exterior ele
começa a estabelecer uma rede de contatos que ele não tinha, mas a grande questão
mesmo é capacitação para começar a colocar o IPT a par do que é de ponta no
mundo (Assessor de Cooperação Internacional - IPT ${ }^{\varpi}$ ).

Analisa-se que o envio dos pesquisadores para o exterior adquirir novos conhecimentos nas suas áreas tem como complemento a aquisição de experiência e conhecimentos dos mercados internacionais para atuação dos IPTs no exterior, similar a abordagem comportamental de internacionalização que destaca a aquisição de experiência e conhecimento para atuação gradual no mercado internacional (JOHANSON; WIEDERSHEIM-PAUL, 1975; JOHANSON; VAHLNE, 1977). Comprova-se ainda este fato, pelas diversas ações internacionais dos IPTs que resultaram do envio de pesquisadores ao exterior.

Conhecemo-los em 2004, num congresso na França. E lá conhecemos o coordenador do projeto com quem foi desenvolvido o projeto.... (pesquisador da área de Redes e Segurança Digital - IPT ${ }^{\varpi}$.

... de um contato que a gente fez, que tava num congresso dos países da língua portuguesa e daí uma visita de uma tarde ela virou um conjunto de iniciativas (pesquisador da área de Recursos Hídricos e Avaliação Geoambiental - IPT ${ }^{\circledR}$ )

Na última a que eu fui conversei com o pessoal da Itália, da Romênia. Até eu tinha um trabalho parecido aqui, eles tinham lá, a gente mandou, trocou informações, isso 
Fabiano Manfio \& João Carlos da Cunha

ajuda! Acaba criando uma rede de contatos e acaba estreitando os laços, porque muitas vezes você conversou com o cara por $e$-mail, assim uma vez, mas encontrar pessoalmente, conversar é difícil, então estreita as relações, vai te atender melhor quando mandar um e-mail, der um telefonema, conversar. Então, sempre ajuda. (pesquisador da área de Eletrônica - LACTEC).

... só que assim, na área das cooperações internacionais é porque alguém foi fazer mestrado ou alguém foi fazer doutorado ou alguém fez lá uma especialização, então eram contatos de pesquisador com pesquisador da instituição e que isso originou um convênio (Diretora de Operações Tecnológicas - LACTEC).

Internacionalmente a gente tem boa relação como pesquisador e tem boa discussão com intercâmbio com pesquisadores e agora está começando a chegar o momento de nós começarmos a fazer parte disso através de convênios e projetos, porque a gente está com a estrutura implantada (pesquisador da área de Biomecânica - IBTeC).

Uma característica encontrada nos Institutos são as ações de cooperação terem um caráter inward também, principalmente no caso do IBTeC com a SATRA e dos pesquisadores do Instituto com pesquisadores de universidades estrangeiras. O IPT ${ }^{\boxplus}$, normalmente as cooperações formalizadas, tem uma mão de duas vias atuando com característica inward e outward. Essa característica vem confirmar Welch e Loustarinen (1993), que destacam a relação direta entre inward e outward em algumas atividades internacionais realizadas pelas organizações, nas quais as ações inward podem preceder e influenciar o desenvolvimento das ações outward.

As ações comerciais inward de importação de máquinas e equipamentos são realizadas esporadicamente por LACTEC e IBTeC. Contudo para o IBTeC representou uma importante ação de implementação e modernização dos seus laboratórios nos anos de 2005 e 2006. Diferentemente para o IPT ${ }^{\circledR}$, constituiu-se numa ação recente e importante para o processo de modernização laboratorial que o mesmo vem implementando.

A importação de máquinas e equipamentos não é uma ação realizada constantemente pelos IPTs, contudo é importante para a atualização dos laboratórios com o que há de mais moderno e proporcionar a realização de $\mathrm{P} \& \mathrm{D}$ qualificada e atender aos padrões nacionais e internacionais. Identifica-se que os IPTs estão cientes desse fator e têm buscado aparelhar-se com os mais modernos equipamentos existentes. Ao analisar o processo de importação de máquinas e equipamentos dos IPTs para atualização de seus processos de P\&D, constata-se que esse tipo de ação inward é fundamental para os Institutos pesquisados terem capacidade produtiva para o desenvolvimento de ações outward.

A importação de matéria-prima é uma ação pouco utilizada pelos Institutos. Embora no IBTeC se caracterize como constante, a atividade tem baixa representatividade na compra total de matérias-primas do Instituto. Esse fator deve-se à característica de os Institutos não se constituírem como indústrias que precisem de grandes quantidades de uma determinada 
Internacionalização dos institutos de pesquisas tecnológicas

matéria-prima, ainda que, alguns componentes são específicos e necessários para o desenvolvimento das atividades. Contribui para isso também o fato de o Brasil ser um país de grandes dimensões e grande quantidade de recursos, onde os IPTs buscam as necessidades de matéria-prima em âmbito nacional para só depois buscar em outros países.

Ainda nas ações comerciais inward, IBTeC e LACTEC destacam-se pelas atividades de cooperação com multinacionais, que além do caráter outward possuem caráter inward. Para o restante das atividades comerciais inward, apenas o LACTEC identificou esse tipo de ação de forma esporádica, no entanto foi dado destaque à especificidade dessas ações, as quais não apresentam grande representatividade para o Instituto.

Nós temos aqui com a Siemens Internacional, a Siemens de Minneápolis, tem a área
de automação, tem um pessoal da Siemens que trabalha aqui, nesse prédio aqui. Eles
são funcionários do LACTEC, mas eles trabalham exclusivamente no
desenvolvimento pra Siemens. Então uma pequena escala a gente tem. [...], mas é
muita tecnologia de interesse da Siemens. Até seria algo constante, mas dentro do
volume do LACTEC não é algo representativo (Diretor Desenvolvimento
Tecnológico).

Dando ênfase a outras questões das atividades de internacionalização dos IPTs pesquisados, um dos aspectos relevantes no processo de internacionalização do IPT ${ }^{\circledast}$ é a utilização da Assessoria de Cooperação Internacional, ou seja, o IPT ${ }^{\circledR}$ possui um departamento de assessoria às ações internacionais e que atua ativamente nesse processo. Diferentemente dos outros dois Institutos pesquisados que não possuem área específica para o desenvolvimento de ações internacionais.

Ainda destaca-se que, efetivamente, nenhum Instituto citou os IPTs internacionais como concorrentes, tanto na atuação no Brasil, como no Exterior. Foram citadas algumas linhas ou setores específicos que, por muitas vezes, se o Instituto não firmar cooperação/parceria com a empresa ou IPT estrangeiro, este buscaria outro Instituto para realizar a cooperação/parceria. Assim, os IPTs declaram que os agentes internacionais, principalmente atuantes na $\mathrm{P} \& \mathrm{D}$, são vistos como possíveis parceiros e não como concorrentes.

Quanto a ações do governo para ajudar o processo de internacionalização dos IPTs, nenhum IPT declarou usufruir de ações diretas desenvolvidas por governos. Contudo indiretamente identificam-se algumas ações que contribuem para esse processo:

a) A modernização dos laboratórios, através da disponibilização de recursos público, que tem gerado expectativa e capacidade laboratorial para atuação internacional dos IPTs.

b) Contratação dos IPTs para prestação de serviços técnicos em missões internacionais do governo. 
Apesar de identificadas essas ações, a promoção por parte do governo de ações que ajudem os IPTs a atuarem internacionalmente é incipiente. Mesmo o Governo Federal, que deveria ter mais interesse em promover a maior integração dos agentes de inovação nacionais com agentes de inovação internacionais, tem desenvolvido poucos incentivos neste sentido.

Complementarmente, destaca-se que as ações que foram caracterizadas como constantemente realizadas pelos Institutos, na sua maioria não apresentam grande magnitude no total das atividades realizadas pelos IPTs. Os IPTs ainda carecem de um incremento nas atividades internacionais para que as mesmas sejam consideradas significativas no conjunto de suas atuações.

Apesar de o IBTeC ser um instituto de pequeno porte e com baixa atuação internacional, suas tímidas ações internacionais demonstram o interesse do Instituto em internacionalizar-se, como, por exemplo, a edição internacional da Revista Tecnicouro, as parcerias internacionais concretizadas, o relacionamento internacional dos pesquisadores e a reestruturação laboratorial do Instituto para atender às demandas nacionais e internacionais de P\&D. As principais dificuldades evidenciadas no processo de internacionalização do Instituto tem sido as limitações de recursos e a falta de um plano específico de atuação internacional.

O LACTEC pode ser considerado um instituto de grande porte e com baixa atuação internacional. Demonstra um claro interesse em internacionalizar-se no discurso dos entrevistados, embora não haja ainda um planejamento para isso (processo em construção) e as ações desenvolvidas ocorram de forma isolada e espontânea. As principais dificuldades enfrentadas são a limitação de recursos, centralização na direção das ações internacionais e a falta de um planejamento de ações internacionais. Contribui também para a baixa atuação internacional a demanda nacional por serviços preencher quase que na sua totalidade a mão de obra de serviços do Instituto, desestimulando e limitando a procura imediata do LACTEC por ações internacionais.

O IPT ${ }^{\varpi}$ é um instituto de grande porte e com uma maior atuação internacional frente aos outros dois casos pesquisados. A internacionalização já entrou na pauta de planejamento do Instituto, principalmente com ações de envio de pesquisadores para estudo e treinamento no exterior. As principais ações desenvolvidas são ações internacionais de interação e cooperação com IPTs e pesquisadores estrangeiros. Destaca-se também a reestruturação administrativa e laboratorial do Instituto para atender aos mercados nacionais e internacionais. 
Internacionalização dos institutos de pesquisas tecnológicas

\section{CONCLUSÕES}

O envolvimento internacional (WELCH; LUOSTARINEN, 1988) dos IPTs caracteriza-se por uma variedade de atividades internacionais inward e outward, que, conforme Welch e Loustarinen (1993), apresentam muitas vezes ligações diretas ou indiretas. Assim sendo muitas das atividades internacionais desenvolvida pelos IPTs se caracterizam por ser inward e outward ao mesmo tempo, como por exemplo, a cooperação, a visita a organizações no exterior, os contatos com pesquisadores estrangeiros e as ações de qualificação no exterior, que levam o Instituto a atuar no exterior e ao mesmo tempo propiciam a absorção e acesso de informações e conhecimentos para a Instituição.

As principais atividades de internacionalização dos IPTs concentram-se na área da cooperação, parcerias e interação dos Institutos a fim de buscar o acesso e troca de informações, conhecimentos e tecnologias com os agentes internacionais. Essas ações caracterizam-se pelo seu processo de continuidade e renovação em novas atividades internacionais.

As atividades comerciais caracterizam-se como ações esporádicas e isoladas, que ainda não constituem um objetivo concreto de atuação internacional dos IPTs. Contudo percebe-se no discurso dos entrevistados a intenção de intensificar essas ações, nas quais o próprio processo de modernização dos IPTs, identificado pela pesquisa nas três instituições pesquisadas, tem o objetivo de preparar os Institutos para atender às demandas de pesquisas nacionais e internacionais.

Outro fator que emerge da análise dos dados é a relevância do pesquisador, e consequentemente, das redes de relacionamentos desses no envolvimento internacional dos IPTs. O relacionamento entre os pesquisadores dos Institutos e pesquisadores estrangeiros é o principal fator indutor para a concretização de parcerias com instituições no exterior. $\mathrm{O}$ surgimento de acordos de cooperação em projetos de $\mathrm{P} \& \mathrm{D}$, sem a influência da rede de relacionamento de algum pesquisador, pode ser caracterizada como rara. A troca de informações e conhecimentos informal entre os pesquisadores é outro fator bastante destacado no processo de envolvimento internacional dos IPTs. Em consequência, destaca-se a importância do investimento institucional no envolvimento internacional dos pesquisadores com vistas ao incremento das atividades internacionais dos IPTs.

$\mathrm{Na}$ análise da internacionalização dos IPTs identifica-se uma grande variedade de atividades internacionais desenvolvidas. Contudo a intensidade dessas atividades é baixa comparada as atividades desenvolvidas em território nacional. O incremento das atividades internacionais dos IPTs requer maior investimento em ações internacionais e um 
Fabiano Manfio \& João Carlos da Cunha

planejamento estratégico dessas ações, algo ainda incipiente nas atividades dos IPTs pesquisados. Constata-se que normalmente as atividades internacionais desenvolvidas emergem do dia a dia dos IPTs e principalmente do interesse de alguns pesquisadores em estar em contato com o ambiente internacional, sem que haja um prévio planejamento da organização - é, portanto, muito mais uma estratégia emergente ao invés de planejada.

A intensificação do processo de internacionalização dos IPTs emerge da necessidade de três fatores que ainda precisam ser aperfeiçoados: planejamento estratégico para a vinculação internacional, maior investimento no ganho de competências para a ação internacional e maior interação entre a instituição e os pesquisadores no desenvolvimento das atividades internacionais.

No âmbito do ambiente externo aos IPTs destaca-se a necessidade de maior apoio dos governos, com investimentos e desenvolvimento de uma política macroeconômica que realize o inter-relacionamento das políticas nacionais de desenvolvimento e as políticas de Ciência Tecnologia e Inovação - C,T\&I. Os IPTs podem contribuir significativamente com a internacionalização das empresas brasileiras e com a maior competitividade destas empresas para suportar o assédio de empresas internacionais ao cobiçado mercado nacional. No entanto o governo Federal deve ser o formulador e coordenador deste plano de aumento da competência tecnológica dos IPTs e setor produtivo nacional.

Os estudos da internacionalização dos Institutos de Pesquisas Tecnológicas são ainda incipientes e necessitam ser aprofundados. Diante disso surgem alguns questionamentos e propostas para serem considerados em pesquisas futuras tais como: atuação internacional dos IPTs como apoio à inserção internacional de empresas brasileiras; atuação dos IPTs em projetos internacionais para o Governo (tais como a nacionalização de produção de medicamentos); a internacionalização dos pesquisadores como parte relevante do processo de internacionalização dos IPTs; e estudos que possam comparar a atuação e competitividade de IPTs nacionais e estrangeiros.

\section{REFERÊNCIAS}

ANDERSON, E.; GATIGNON, H. Modes of foreign entry: a transaction cost analysis and propositions. Journal of International Business Studies, v.17, n.3, p.1-19, 1986.

ANDERSSON, S. The internationalization of the firm from an entrepreneurial perspective. International Studies of Management \& Organization, v.30, n.1, p.63-92, 2000. 
BUCKLEY, P. J.; CASSON, M. C. A theory of international operations (1979). In: BUCKLEY, P. J.;GHAURI, P. N. The Internationalization of the Firm. London: Academic Press, 1993.

Analyzing foreign market entry strategies: extending the internalization approach. Journal of International Business Studies, v.29, n.3, p.539-561, 1998.

CARLSSON, B. Internationalization of innovation systems: a survey of the literature. Research Policy, v.35, n.1, p.56-67, 2006.

COSTA, K. D. S. A internacionalização da educação superior. In: $31^{\text {a }}$ Reunião Anual da Associação Nacional de Pós-Graduação e Pesquisa em Educação - ANPEd, 19 a 22 de outubro de 2008, Caxambu - MG. Anais... Rio de Janeiro: ANPEd, 2008.

DUNNING, J. H. The electric paradigm of international production: A restatement and same possible extensions. Journal of International Business Studies, v.19, n.1, p.1-31, 1988.

The eclectic paradigm as an envelope for economic and business theories of MNE activity. International Business Review, v.9, p.163-190, 2000.

The eclectic paradigm of international production: past, present, and future. International Journal of the Economics of Business, v.8, n.2, p.173-190, 2001.

HYMER, S. The international operations of national firms: a study of direct foreign investment. Doctorate Thesis, Cambridge, MA: The MIT Press. 1976

IMBERT, C.; CHARLES, H. Parcerias inteligentes: explorando sinergias entre organizações de pesquisa tecnológica e o subsetor de serviços profissionais em países em desenvolvimento. In: Gestão de Institutos de Pesquisa Tecnológica, 18 a 20 de outubro de 2000, Fortaleza. Anais... Brasília: ABIPTI, 2000. 
JOHANSON, J.; VAHLNE, J. E. The internationalization process of the firm - a model of knowledge development and increasing foreign market commitments. Journal of International Business Studies, v.8, n.1, p.23-33, 1977.

JOHANSON, J.; WIEDERSHEIM-PAUL, F. The internationalization of the firm: Four Swedish Cases. Journal of Management Studies, v.12, n.3, p.305-322, 1975.

KOGUT, B. International management and strategy. In: THOMAS, H. P., ANDREW M.; WHITTINGTON, RICHARD. Handbook of Strategy and Management. Londres: Sage Publications Inc, 12, p.261-278, 2002.

LACTEC. Instituto de Tecnologia para o Desenvolvimento. 2008. Disponível em: $<$ http://www.lactec.org.br/>, Acesso em: Out 2008.

MACULAN, A. M.; ZOUAIN, D. M. Mudanças na gestão das instituições de P\&D: a experiência do INT. In: ENCONTRO DA ASSOCIAÇÃO NACIONAL DE PROGRAMAS DE PÓS-GRADUAÇÃO EM ADMINISTRAÇÃO, 21ㅜ, 1997, Rio das Pedras. Anais... Rio das Pedras: ANPAD, 1997.

MCDOUGALL, P. P.; OVIATT, B. M. International entrepreneurship: the intersection of two research paths. Academy of Management Journal, v.43, n.5, p.902-906, 2000.

The internationalization of entrepreneurship. Journal of International Business Studies, v.36, n.1, p.2-8, 2005.

MCDOUGALL, P. P.; SHANE, S.; OVIATT, B. M. Explaining the formation of international new ventures: the limits of theories from international business research. Journal of Business Venturing, v.9, n.6, p.469-486, 1994.

MELIN, L. Internationalization as a strategy process. Strategic Management Journal, v.13, p.99-118, 1992.

MIURA, I. K. O processo de internacionalização da Universidade de São Paulo: um estudo de três áreas do conhecimento. Tese de Doutorado em Administração, Ribeirão 
Preto: Faculdade de Economia, Administração e Contabilidade de Ribeirão Preto (FEA-RP) da Universidade de São Paulo (USP), Departamento de Administração da FEA-RP/USP. 2006

MOROSINI, M. C. Estado do conhecimento sobre internacionalização da educação superior: conceitos e práticas. Revista Educar, v.28, p.107-124, 2006.

NEUMAN, L. W. Social research methods: qualitative and quantitative approaches. 3 ed. Boston: Allyn \& Bacon, 2002.

OECD. Sciency Technology and Industry Outlook 2006. OECD Publications. Paris. 2006

PARKER, B. Evolução e revolução: da internacionalização à globalização. In: CLEGG, S. R., et al. Handbook de estudos organizacionais, São Paulo: Atlas, p.400-433, 1999.

ROOT, F. R. Entry Strategies for International Markets. . New York: Lexington Books, 1994.

RUGMAN, A. M. The international operations of national firms: a study of direct foreign investment. Journal of International Business Studies (pre-1986), v.9, n.2, p.103-125, 1978.

SALLES-FILHO, S. Ciência, tecnologia e inovação: a reorganização da pesquisa pública no Brasil. Campinas: Editora Komedi, 2000. 416 p.

SALLES-FILHO, S.; BONACELLI, M. B. Promoção da Ciência, Tecnologia e Inovação a partir da redefinição do papel dos institutos e centros de pesquisa e desenvolvimento no país. In: XI SEMINÁRIO LATINO-IBEROAMERICANO DE GESTIÓN TECNOLÓGICA, 2005, Salvador. Anais... Salvador: ALTEC, 2005a.

Trajetórias e agendas para os institutos e centros de pesquisa no Brasil. In. Revista Parcerias Estratégicas. Brasília: Centro de Gestão de Estudos Estratégicos, v.20, n. 5, p.1485-1513, 2005b. 
SCHNEIDER, C. A. Fornecer soluções tecnológicas inovadoras e competitivas: a razão de ser e garantia de sustentabilidade de uma instituição de pesquisa e desenvolvimento tecnológico. In: Gestão de Institutos de Pesquisa Tecnológica, 18 a 20 de outubro de 2000, Fortaleza. Anais... Brasília: ABIPTI, 2000.

SOLBERG, C. A.; DURRIEU, F. Access to networks and commitment to internationalisation as precursors to marketing strategies in international markets. Management International Review, v.46, n.1, p.57-83, 2006.

STALLIVIERI, L. O processo de internacionalização da Universidade de Caxias do Sul. $2005 . \quad$ Disponível em: $<$ http://www.ucs.br/ucs/tplCooperacaoInterno/copy_of_cooperacao/assessoria/artigos/internac ionalizacao_ucs.pdf>, Acesso em: Dez 2008.

SULLIVAN, D. Measuring the degree of internationalization of a firm. Journal of International Business Studies, v.25, n.2, p.325-342, 1994.

TEECE, D. J. Reflections on the Hymer thesis and the multinational enterprise. International Business Review, v.15, n.2, p.124-139, 2006.

TOYNE, B. International exchange: a foundation for theory building in. Journal of International Business Studies, v.20, n.1, p.1-21, 1989.

VERNON, R. International investment and international trade in the product cycle. Quarterly Journal of Economics, v.80, p.190-207, 1966.

The product cycle hypothesis in a new international environment. Oxford Bulletin of Economics and Statistics, v.41, n.4, p.255-267, 1979.

WAITRO. Best Practices for the Management of Research and Technology Organizations Special Report 2008. Disponível em: $<$ http://www.waitro.org/modules/wfsection/article.php?page $=1 \&$ articleid=23>, Acesso em: Abr 2008.

WEISS, R. S. Learning from strangers. New York: Free Press, 1994. 
Internacionalização dos institutos de pesquisas tecnológicas

WELCH, L. S.; LUOSTARINEN, R. Internationalization: evolution of a concept. Journal of General Management, v.14, n.2, p.34-49, 1988.

WELCH, L. S.; LUOSTARINEN, R. K. Inward-outward connections in internationalization. Journal of International Marketing, v.1, n.1, p.44-56, 1993.

YIN, R. K. Estudo de caso: planejamento e métodos. 3. ed. Porto alegre: Bookman, 2005. 
Fabiano Manfio \& João Carlos da Cunha

\section{ANEXO A}

QUADRO DE ATIVIDADES DE INTERNACIONALIZAÇÃo

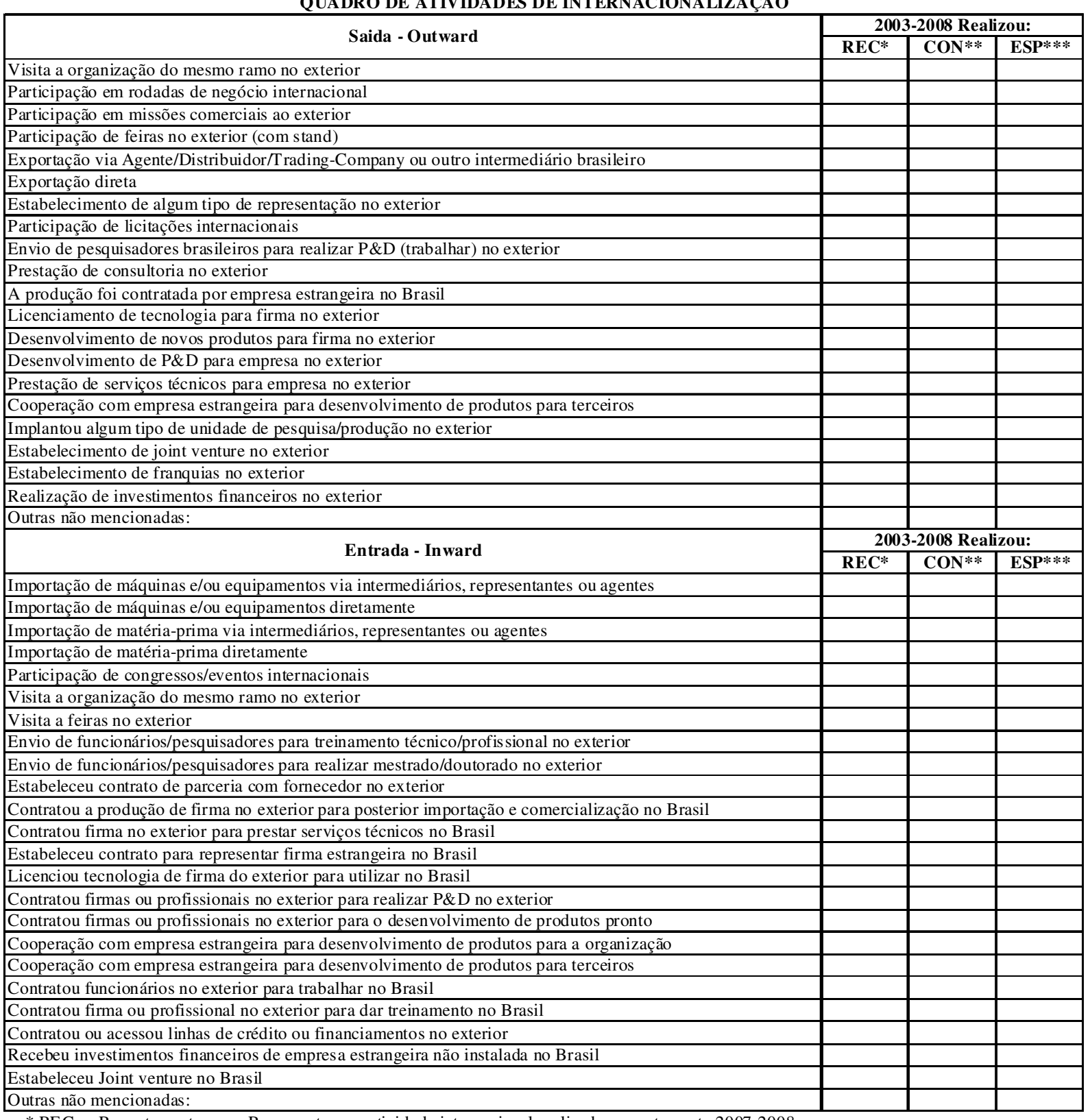

* REC: Recentemente - Representa uma atividade internacional realizada rescentemente 2007-2008.

** CON: Constantemente - Representa uma atividade internacional constante, que realizou-se ou afetou a empresa por mais de 2 anos.

*** ESP: Esporadicamente - Representa uma atividade internacional esporadica, que realizou-se uma ou duas vezes nesse período, sem afetar significativamente a empresa. 